\title{
Characterizing CEACAM5 interaction with CD8 $\alpha$ and CD1d in intestinal homeostasis
}

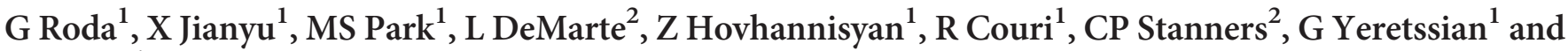 \\ L Mayer $^{1}$
}

Normal intestinal epithelial cells (IECs) could act as non-professional antigen-presenting cells, selectively activating $\mathrm{CD}^{+}{ }^{+}$-suppressor T cells. An epithelial cell surface glycoprotein, gp180, recognized by monoclonal antibodies B9 and L12 was determined to be critical in this process. Purification and sequence analysis of mAb B9 reactive material revealed amino-acid sequence homology with CEACAM5. We demonstrate that CEACAM5 has properties attributed to gp180, such as CD8 $\alpha$ binding and activation of CD8-associated Lck. CEACAM5 is the only CEACAM member interacting with CD1d through the B3 domain. Its $\mathrm{N}$ domain (recognized by B9) is required for CD8 $\alpha$ binding. Removal of the $\mathrm{N}$-domain glycosylated residues reduces B9 recognition, CD8 $\alpha$ binding affinity, and activation of LcK. Therefore, conformational changes in CEACAM5 glycosylation site are critical for its interaction with CD8 $\alpha$. CEACAM5-activated $\mathrm{CD}^{+} \mathrm{T}$ cells acquire the ability to suppress the proliferation of $\mathrm{CD} 4^{+} \mathrm{T}$ cells in vitro in the presence of interleukin (IL)-15 or IL-7. We provide new insights into the role of CEACAM5 and define its specific immunoregulatory properties among the CEACAMs expressed on IECs. We suggest that unique set of interactions between CEACAM5, CD1d, and CD8 render CD1d more class I-like molecule, facilitating antigen presentation and activation of CD ${ }^{+}$-suppressor regulatory $\mathrm{T}$ cells.

\section{INTRODUCTION}

The nature of the immune response in the intestine may require either immunosuppression or controlled inflammation. The suppressive state is dictated by several factors, including regulatory $\mathrm{T}$ (Treg) cells, non-T cells, and unique antigenpresenting cells. Many laboratories, as well as ours, have described the role of intestinal epithelial cells (IECs) as nonprofessional antigen-presenting cells. ${ }^{1-7} \mathrm{CD}^{+}$Treg cells can be activated by IECs through the complex formed by the nonclassical I molecule, CD1d, and gp180 on IECs. Moreover, we have recently demonstrated that $\mathrm{CD} 8^{+}$T-cell lines derived from lamina propria lymphocytes of Crohn's disease patients are defective in their suppressive activity. In this scenario, the addition of IEC produced interleukin (IL)-15 or IL-7 cytokines was critical to establish and especially to sustain long-term $\mathrm{CD}^{+}{ }^{+}$T-cell cultures. ${ }^{8}$ We have characterized gp180 as a surface glycoprotein recognized by two anti-epithelial cell mAbs, B9 and L12. Affinity-purified gp180 has been shown to bind to CD1d and CD8 $\alpha$ and to increase CD8-associated Lck kinase activity. Subsequently, CD1d becomes more class I-like molecule, with enhanced CD1d binding to the T-cell receptor and gp180 binding to CD8 $\alpha$. In IEC:T-cell co-culture experiments, mAbs B9 and L12 block the selective proliferation of $\mathrm{CD}^{+}{ }^{+} \mathrm{T}$ cells and inhibit the ability of IECs to phosphorylate and activate Lck. $^{9-19}$ Furthermore, using mAb B9 we have demonstrated that gp180 expression was significantly decreased in non-inflamed tissues derived from inflammatory bowel disease (IBD) patients. This defect correlated with the inability of IBD IECs to activate CD8 ${ }^{+}$Treg cells. ${ }^{20}$

The carcinoembryonic antigen (CEA) family belongs to the immunoglobulin (Ig) gene superfamily consisting of the CEACAM subgroup and the pregnancy-specific glycoprotein. While the pregnancy-specific glycoprotein is secreted, CEACAM subfamily proteins are heavily glycosylated cell surface proteins. They are either transmembrane or glycophosphatidyl-inositol (GPI)-linked. Analysis of the amino-acid sequences reveals a distinct domain organization among the family members. Two types of Ig domains are observed in the ${ }_{1}^{1}$ Immunology Institute, Mount Sinai School of Medicine, New York, New York, USA and ${ }^{2}$ Goodman Cancer Center and Department of Biochemistry, McGill University,
Montreal, Quebec, Canada. Correspondence: G Roda or L Mayer (giulia.roda@mssm.edu or Iloyd.mayer@mssm.edu)

Received 21 February 2013; accepted 6 September 2013; published online 9 October 2013. doi:10.1038/mi.2013.80 
CEA family members: an N-terminal domain that is homologous to the Ig variable domain (IgV-like) and 0-6 C-terminal domains that are homologous to the Ig constant domain (IgC-like). The IgC-like domain may be either of type A or type B. CEA is expressed in columnar IECs and goblet cells of the colon, in mucous neck cells and pyloric mucous cells of the stomach, in squamous epithelial cells of the tongue, esophagus and cervix, and in the pancreatic duct. Various reports have described a role for CEA family members in cell-cell adhesion engaging homotypic and heterotypic interactions through their $\mathrm{N}$-terminal domains. Several members have been described to act as pathogen sensors, suggesting a possible role of CEA in the host-pathogen crosstalk..$^{21-31}$

We now report that affinity-purified gp180 shows sequence homology with the N-terminal domain of CEACAM5, and we demonstrate that both gp180 and CEACAM5 share common binding and functional properties. We further unravel that CEACAM5 possesses a highly specific positive immunoregulatory function compared with the other four CEACAM family members expressed on IECs. Finally, we delineate a unique set of interactions between CEACAM5/CD1d and CEACAM5/ $\mathrm{CD} 8$, and for the first time, we provide evidence that CEACAM5 give rise to $\mathrm{CD} 8{ }^{+} \mathrm{T}$ cells with potent suppressor functions.

\section{RESULTS}

\section{CEACAM5 shares homology with gp180 and is recognized by $\mathrm{B} 9 \mathrm{mAb}$}

To determine the specific target protein of the $\mathrm{mAb} B 9$, gp180 was purified by immuno-affinity using $\mathrm{mAb} B 9$ and subjected to amino terminal sequencing by Edman degradation. The first 25 amino acids showed 100\% sequence homology with CEACAM5 (Figure 1a). Other CEACAM family members did not exhibit similarities with the obtained gp180 sequence (data not shown). The congruence between the molecular weights and the $\mathrm{N}$-terminal amino-acid sequences of gp180 and CEACAM5 strongly supports the contention that these proteins are identical.

Given the N-terminal sequence homology to CEACAM5, we questioned whether this member of the CEACAM family expressed the epitope recognized by $\mathrm{mAb} \mathrm{B} 9$. We overexpressed CEACAM5 in 293T and FO-1 cells and assessed protein expression by western blotting. HT29 cells were used as positive control as these cells express endogenous CEACAM5. Our results clearly show that CEACAM5 is recognized by B9 and Col-1 (anti-CEA that recognizes A and B domains) mAbs (Figure 1b).

\section{Identification of the B9 epitopes on CEACAM5}

Alignment of CEACAM5 with CEACAM1 or CEACAM6 shows diversity in the amino-acid sequence within the region between residues 42 and 46 of the $\mathrm{N}$ domain. Therefore, we generated mutants of CEACAM5 carrying a deletion of this region $\left(\mathrm{N}^{42} \mathrm{RQII}\right)$ or a single-point mutation in the vicinity of this region $\left(\mathrm{K}^{35} \mathrm{~A}\right)$ to determine the epitope of CEACAM5 recognized by B9. Flow cytometry analysis of CEACAM5 a

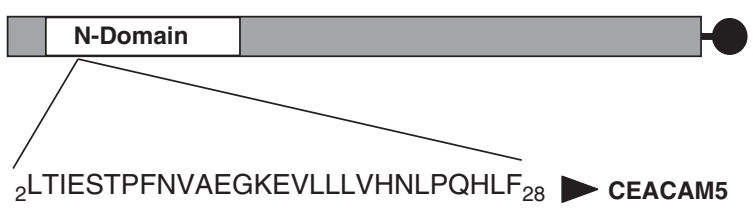

LTIESTPFNVAEGK LLLVHNLPQ LF

LTIESTPFNVAEGK-- LLLVHNLPQXLF g

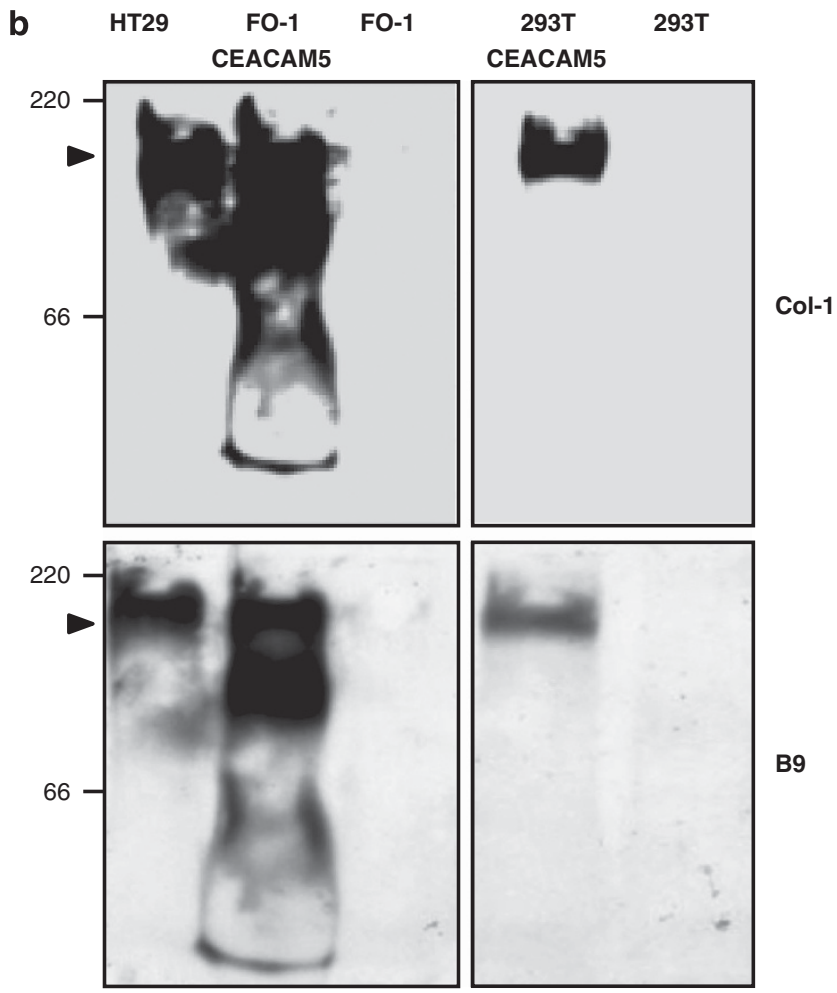

Figure 1 CEACAM5 share homology with gp180 and is recognized by $\mathrm{B} 9 \mathrm{mAb}$. (a) Amino-terminal sequence of the specific target protein of the mAb B9, gp180, and CEACAM5. The first 25 amino acids showed $100 \%$ sequence homology with CEACAM5. (b) Immunoblotting for CEACAM5 in lysates obtained from HT29, as well as from FO-1 and 293T cells, transfected with CEACAM5. B9 and Col-1 monoclonal antibodies were used for western blotting. Non-transfected FO-1 and 293T cells were used as negative control. Data are representative of three independent experiments.

expressing $\mathrm{CHO}$ cells revealed that a large percentage of cells positive for $\mathrm{T} 84.66$, a $\mathrm{mAb}$ that recognizes the $\mathrm{A}$ and $\mathrm{B}$ domains of CEACAM5, were also positive for B9. Although the mutant $\mathrm{K}^{35} \mathrm{~A}$ did not affect the reactivity of B9 with the cells, $\mathrm{N}^{42} \mathrm{RQII}$ strongly reduced B9 staining (Figure 2a). Interestingly, expression of the N70,81A mutant of CEACAM5, which prevents $\mathrm{N}$-domain glycosylation, appears to significantly decrease B9 staining, confirming our previous data that treatment of gp180 with N-glycanase results in loss of the epitope recognized by $\mathrm{mAb} \mathrm{B} 9^{9}$ (Figure 2a).

\section{B9 mAb recognizes other CEACAM family members}

To further evaluate the binding between CEACAM5 and B9 $\mathrm{mAb}, \mathrm{CHO}$ cells overexpressing the four different CEACAM 

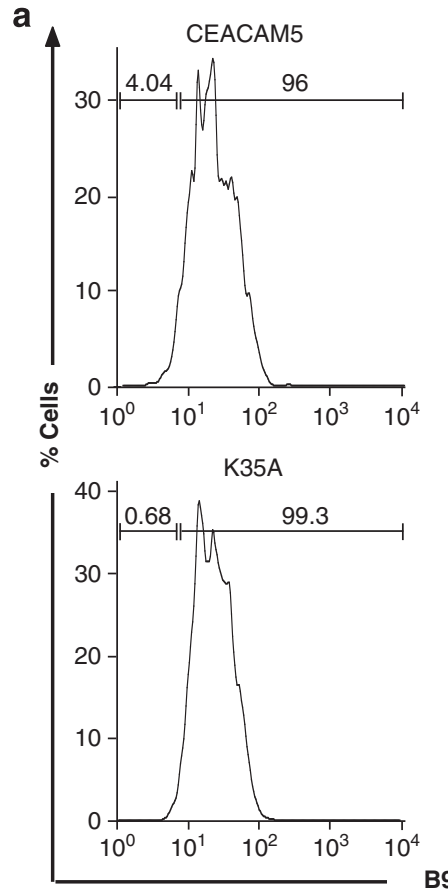
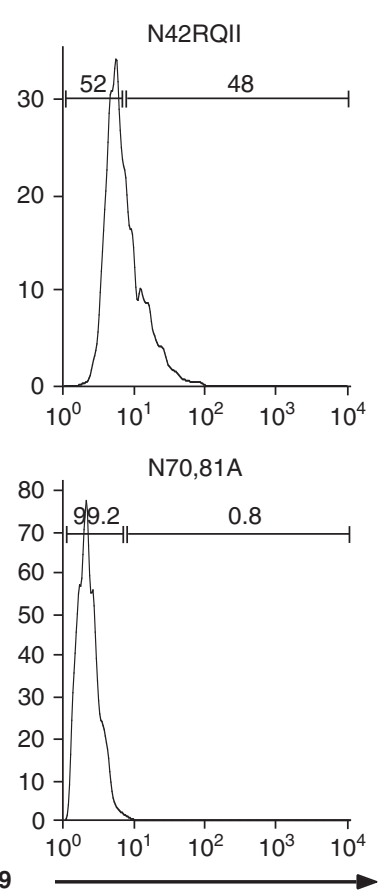

b
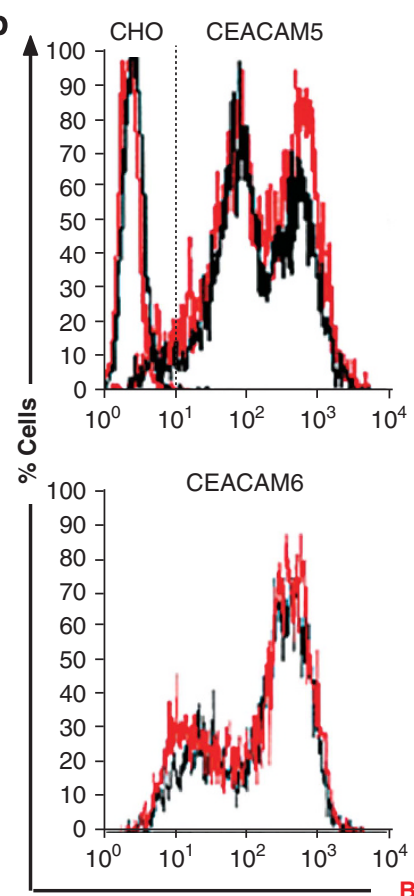
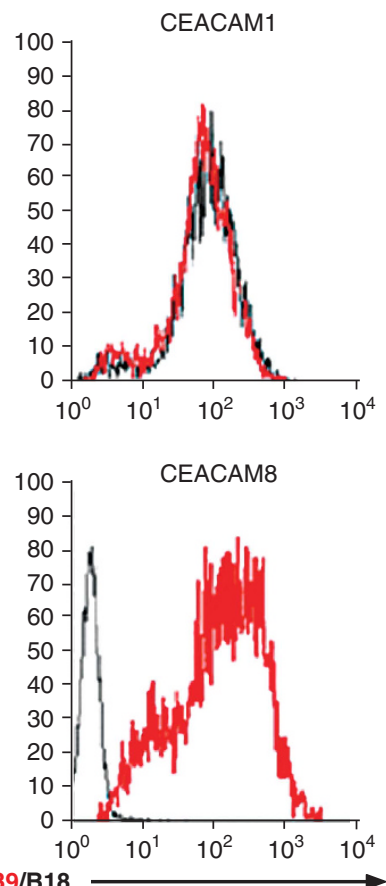

Figure 2 B9 recognizes different CEACAMs expressed on intestinal epithelial cells but specifically binds to a unique region in the $\mathrm{N}$ domain of CEACAM5. (a) Cytofluorimetric profiles of CHO cells transfected with wild-type CEACAM5, a N ${ }^{42} \mathrm{RQII}$ deletion mutant, and point mutants $\mathrm{K} 35 \mathrm{~A}$ and N70,81 A and double-stained with mAb T84.66 and mAb B9. B9 reactivity was reduced with cells expressing the deletion mutant and the sugarless mutant of CEACAM5. (b) Cyto-fluorimetric profiles of CHO cells expressing CEACAM5 or CEACAM1-4L, CEACAM6, and CEACAM8, labeled with B9 or B18 mAbs. B9 can recognize all the four CEACAM members. Data are representative of three independent experiments.

family members (CEACAM1-4L, 5, 6, and 8) were incubated with mAbs B9 and B18 (anti-CEA that recognizes epitopes in the C-terminal domain) and analyzed by flow cytometry. Indeed, CEACAM5 bound to $\mathrm{B} 9 \mathrm{mAb}$ in $\mathrm{CHO}$ cells confirming their interaction (Figure 2b). These data suggest that CEACAM5 harbors a domain that is similar or identical to the B9 epitope. Moreover, B9 mAb recognized CEACAM6, CEACAM1-4L, and CEACAM8 but not a non-transfected $\mathrm{CHO}$ cell line (Figure $\mathbf{2 b}$ ). Thus, several CEACAM family members share a common domain similar to the B9 epitope in their N-terminal region and would conceivably have the immunosuppressive function of CEACAM5.

\section{CEACAM5 binds to CD1d through the B3 domain}

To assess which member of the CEACAM family has binding properties to CD1d, we co-expressed different CEACAMs and CD1d in 293T cells and performed co-immunoprecipitation experiments using the anti-CD1d antibody D5. Our results demonstrate that only CEACAM5 but not CEACAM1 or CEACAM6 interact with CD1d revealed by western blotting analysis using B9 mAb (Figure 3a and see Supplementary Figure S1a online). To ascertain the CEACAM5/CD1d binding, we additionally performed the reverse co-immunoprecipitation experiments using the $\mathrm{B} 9 \mathrm{mAb}$. The data illustrated in Figure $\mathbf{3 b}$ and Supplementary Figure S1b online confirm that only CEACAM5 interacts with CD1d. All CEACAM family members contain an extracellular $\mathrm{N}$-terminal $\mathrm{IgV}$-like and various $\mathrm{C}$-terminal $\mathrm{IgC}$-like domains that are a

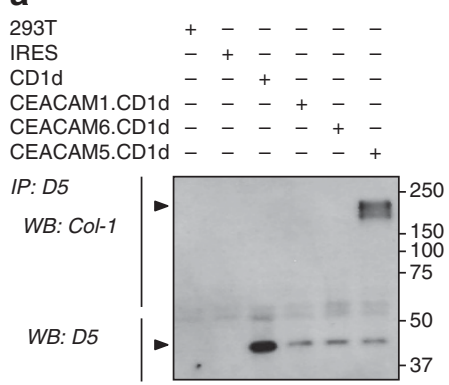

Figure 3 CEACAM5, but not CEACAM1 or CEACAM6, binds to CD1d. 293T cells were co-transfected with pcDNA3.1-IRES-CD1d alone or together with CEACAM1, CEACAM5, or CEACAM6. The cell lysate was co-immunoprecipitated with mouse IgG2b anti-CD1d (D5) or with mouse IgG1 anti-gp180 (B9) antibodies. Western blotting (WB) were performed with Col-1 and D5 mAbs. Data are representative of three independent experiments. IP, immunoprecipitation.

designated as type A or type B domains. By comparing the sequences of CEACAM1, 5, and 6, we found limited homology within the CEACAM family members in the A2 and B3 (B1 for CEACAM1 and CEACAM6) domains. To further characterize which domain of CEACAM5 is involved in the interaction with CD1d, we generated different deletion mutants of CEACAM5 (Figure 4a) and performed co-immunoprecipitation experiments as described above. Neither deletion of the $\mathrm{N}$-terminal region nor of the $\mathrm{A} 2$ domain contributes to the interaction between CEACAM5 and CD1d (Figure $4 \mathbf{b}$ ). In 

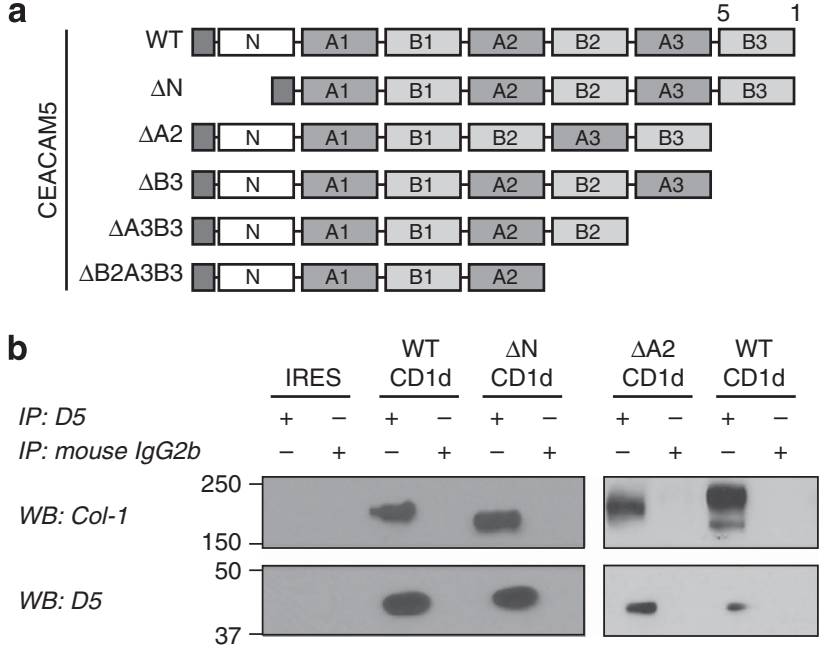

C

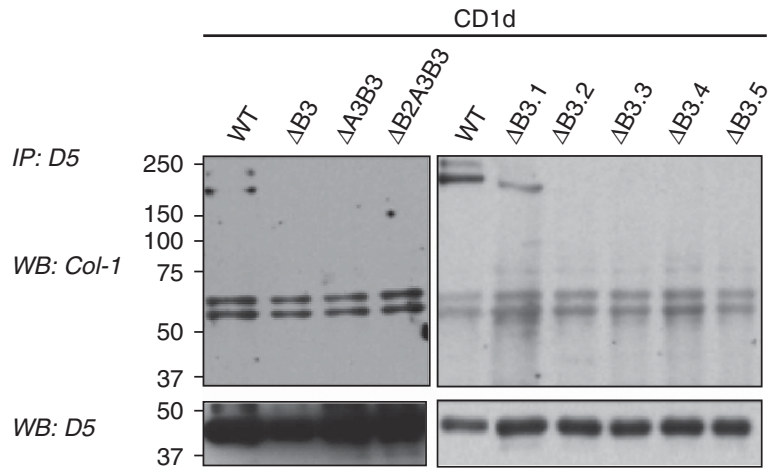

Figure 4 The B3 domain of CEACAM5 is involved in its interaction with CD1d. 293T cells were transfected with expression vectors pCDNA3.1-IRES expressing CD1d and wild-type (WT) or truncated CEACAM5. The cell lysate of the transfectants was immunoprecipitated (IP) with mouse IgG2b anti-CD1d (D5). Western blotting (WB) was then performed with Col-1 and D5 mAbs. (a) Schematic rapresantation of deletions of the $\mathrm{N}$ domain, $\mathrm{A} 2$ domain, and C-terminal truncations. (b) WT and CEACAM5 with the deletion of $\mathrm{N}$ domain $(\mathrm{N})$ co-immunoprecipitate with CD1d. WT and CEACAM5 with the deletion of A2 domain (A2) co-immunoprecipitate with CD1d. (c) CEACAM5 with the sequential C-terminal truncations of each domain fails to co-immunoprecipitate with CD1d. CEACAM5 with the deletion of fragment 1 of B3 domain co-immunoprecipitates with CD1d. With further deletion of the B3 domain, CEACAM5 fails to co-immunoprecipitate with CD1d. Data are representative of three independent experiments.

contrast, sequential C-terminal truncations of each domain allowed us to determine that deletion of the $\mathrm{B} 3$ domain obliterated the ability of CEACAM5 to bind to CD1d (Figure 4c and see Supplementary Figure S2 online). We then performed sequential deletions within the $\mathrm{B} 3$ domain and found that the interaction between CD1d and CEACAM5 depends upon the integrity of fragments $2-5$ of the $\mathrm{B} 3$ domain. Deletion of this region completely abrogated the CEACAM5-CD1d binding (Figure 4c and see Supplementary Figure S2).

\section{CEACAM 5 binds to CD $8 \alpha$ chains and induces the phosphorylation of CD8-associated kinase Lck}

CEACAM5 exists as a GPI-anchored glycoprotein on the surface of IECs. The molecule can therefore be removed by cleaving the anchor with the enzyme phosphoinositide phospholipase C (PIPLC) as previously described. ${ }^{9}$ CEACAM5 released from transfected 293T cells by PIPLC treatment was used in a series of absorption studies. First, we assessed by Western blotting the levels of CEACAM5 in the supernatants of 293T cells transfected with CEACAM5 or empty control vector and treated with PIPLC (Sup1). HT29 cells were used as positive control. Next, melanoma cell line FO-1 as well as murine hybridoma $\mathrm{T}$ cells expressing either human CD4 (3G4) or human $\mathrm{CD} 8 \alpha$ (3G8) were co-cultured with Sup1, and the amount of remaining CEACAM5 was evaluated in the supernatants (Sup2) using Col-1 antibody. This will be indicative of how much CEACAM5 was absorbed by CD4 or $\mathrm{CD} 8 \alpha$ expressed on the T cells. Our results show that CEACAM5 levels in Sup2 were decreased when incubated with 3G8 cells, suggesting that CEACAM5 present in Sup1 was absorbed by $\mathrm{CD} 8 \alpha$ on these T cells (Figure 5a).

Furthermore, we performed similar experiments using human IEC T84 cells that express several CEACAMs on their surface. Absorption of CEACAM5 from the Sup 1 by either CD4 or $\mathrm{CD} 8 \alpha$ was determined by immunoblotting using $\mathrm{B} 9$ and Col1 antibodies. Human $\mathrm{CD} 8 \alpha$ but not $\mathrm{CD} 4$ expressing hybridoma cells were capable of absorbing the B9 reactive material (Figure 5b). Interestingly, these findings are consistent with functional properties previously ascribed to gp 180. To determine whether binding to $\mathrm{CD} 8 \alpha$ had functional significance, we evaluated CEACAM5's ability to induce the phosphorylation of CD8-associated kinase Lck. Using Western blotting analysis, we observed an increase in p-Lck levels $15 \mathrm{~min}$ after treatment of 3G8 cells with purified CEACAM5 (Figure 5c and see Supplementary Figure S3a). We further validated the activation of Lck by flow cytometry analysis in freshly isolated human peripheral blood $\mathrm{CD}^{+} \mathrm{T}$ cells. Phosphorylation of Lck occurred in a time-dependent manner following treatment of $\mathrm{CD} 8^{+} \mathrm{T}$ cells with purified CEACAM5 peptide, OKT8 (anti-CD8 mAb), or Sup1 from T84 cells with PIPLC (Figure 5d). In contrary, CD4 ${ }^{+} \mathrm{T}$ cells stimulated with purified CEACAM5 or OKT8 did not show any increase in LcK phosphorylation. Moreover, we evaluated whether CEACAM5 induces phosphorylation of ZAP70, a $\mathrm{CD} 3 \zeta$-chain-associated protein kinase. Similar to LcK activation, purified CEACAM5 induced phosphorylation of ZAP70 in a time-dependent manner (see Supplementary Figure S3b,c). These data suggest that CEACAM5 not only specifically binds to $\mathrm{CD} 8 \alpha$ but similarly to gp180 induces phosphorylation and activation of CD8-associated Lck.

\section{CEACAM5-CD8 $\alpha$ interaction is dependent on a specific glycosylation site within the $\mathrm{N}$ domain}

To define the binding affinity between wild-type (WT) CEACAM5 and $\operatorname{CD} 8 \alpha$, we used the Biacore system, where one molecule (soluble ligand $\mathrm{CD} 8 \alpha$ or control CD4) is immobilized on a dextran matrix and the putative analyte in solution (CEACAM5 WT or mutants) is passed over the surface (Figure 6a and see Supplementary Figure S4). A full kinetic analysis of WT CEACAM5/CD $8 \alpha$ binding revealed that 
a

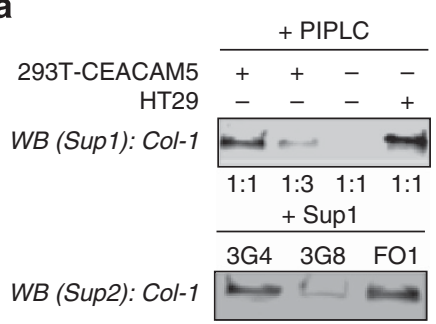

b

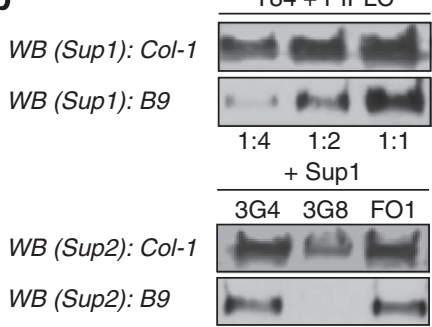

c

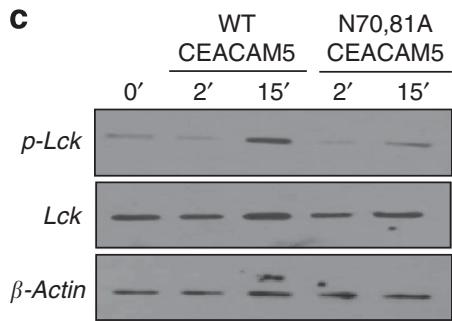

d

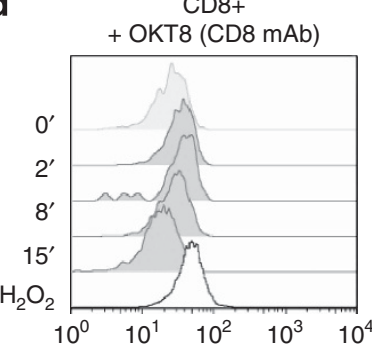

CD8+
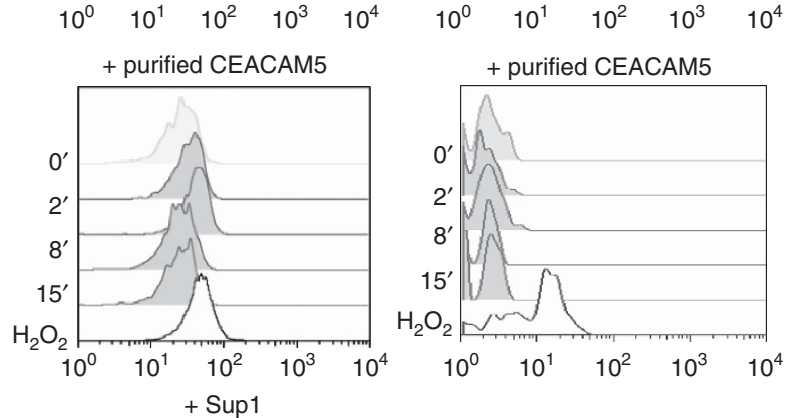

CD4+
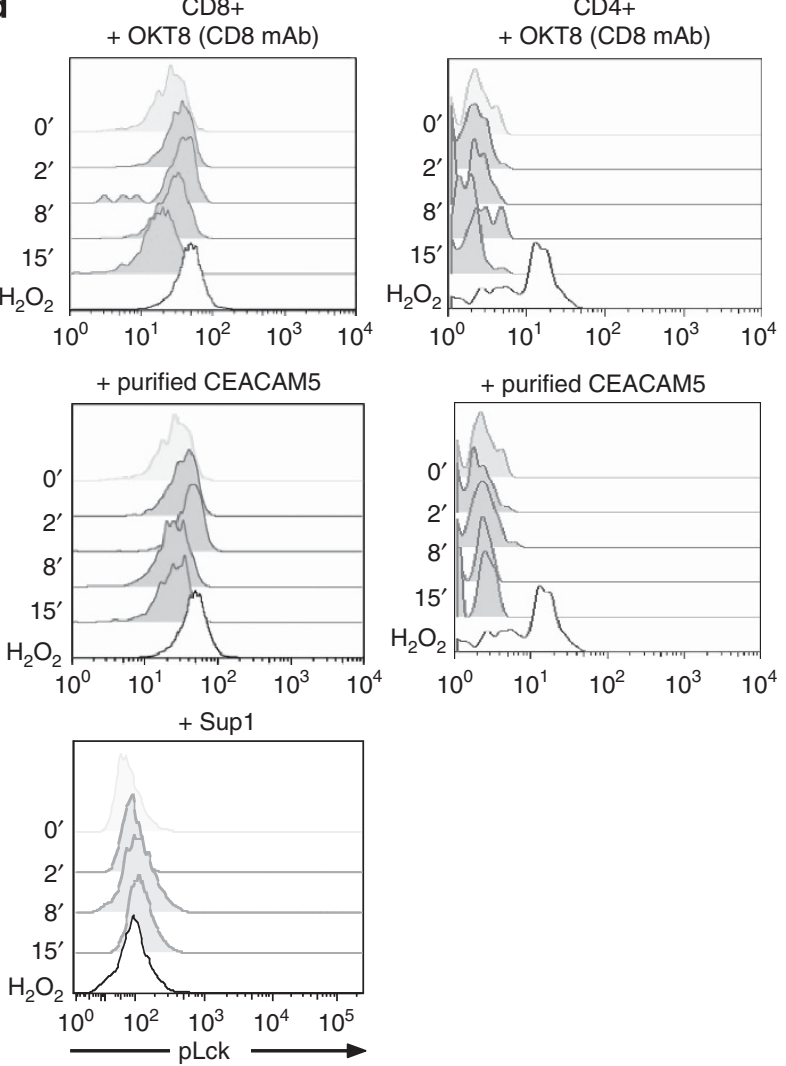

Figure 5 CEACAM5 binds CD8 $\alpha$ and induces phosphorlylation of CD8-associated LCK. (a) $3 G 4$ and $3 G 8$ cells were incubated with phosphoinositide phospholipase C (PIPLC) supernatants from CEACAM5 transfectants, vector control 293 T cells, or (b) intestinal epithelial cells cell line T84. FO-1 cells were used as negative control. Absorbed or unabsorbed supernatants were subjected for immunoblotting using Col-1 or B9 mAbs. 3 G8 but not 3G4 were capable of absorbing CEACAM5. Data are representative of three independent experiments. (c) 3G cells were incubated with purified CEACAM5 for different time points and subjected to immunoblotting for anti-phosphoLcK mAb. At 15', CEACAM5 induce phosphorylation of LcK. Data are representative of three independent experiments. (d) Flow cytometry analysis of $p$-Lck staining in human peripheral $\mathrm{CD} 8{ }^{+} \mathrm{T}$ cells and $\mathrm{CD} 4^{+} \mathrm{T}$ cells stimulated with Sup1, mAb CD8, and CEACAM5-purified peptide for different time points. $\mathrm{H}_{2} \mathrm{O}_{2}$ represents the positive control. Data are representative of five independent experiments.

a

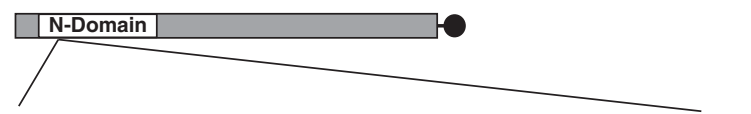

HLFGYSWYKG ERVDGNRQII GYVIGTQQAT PGPAYSGREI IYPNASLLIQ NIIQNDTGFY WT HLFGYSWYKG ERVDG GYVIGTQQAT PGPAYSGREI IYPNASLLIQ NIIQNDTGFY N ${ }^{42}$ RQII HLFGYSWYKG ERVDGDRQII GYVIGTQQAT PGPAYSGREI IYPNASLLIQ NIIQNDTGFY N42D HLFGYSWYAG ERVDGNRQII GYVIGTQQAT PGPAYSGREI IYPNASLLIQ NIIQNDTGFY K35A HLFGYSWYKG ERVDGNRQII GYVIGTQQAT PGPAYSGREI IYPAASLLIQ NIIQADTGFY N70,81A 35 42

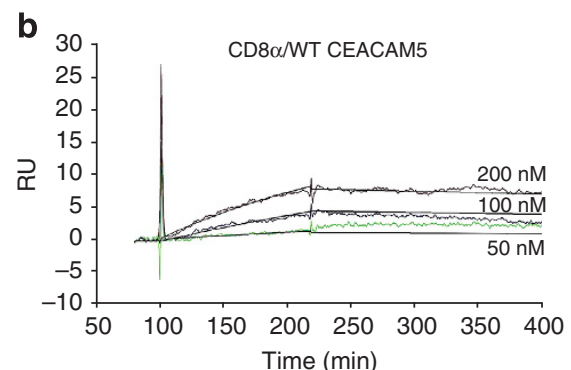

C 81 d

\begin{tabular}{|l|c|}
\hline & $\boldsymbol{K}_{\boldsymbol{D}}(\boldsymbol{M})$ \\
\hline WT & $2.2 \mathrm{E}-08$ \\
\hline $\mathrm{N}^{42} \mathrm{RQII}$ & $1.8 \mathrm{E}-08$ \\
\hline $\mathrm{N} 42 \mathrm{D}$ & $3.8 \mathrm{E}-08$ \\
\hline K35A & $1.5 \mathrm{E}-07$ \\
\hline N70,81A & $1.6 \mathrm{E}-05$ \\
\hline
\end{tabular}

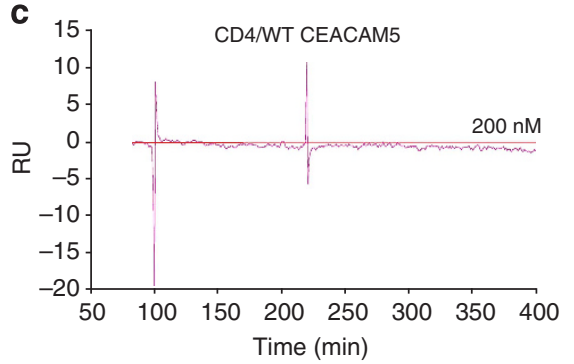

Figure 6 Removal of N-domain sugar bridge reduces CEACAM5-CD8 $\alpha$ binding affinity. (a) Schematic representation of CEACAM5 $\mathrm{N}$-domain mutants. (b) Binding of soluble wild-type CEACAM5 (WT) to immobilized CD8 $\alpha$ peptide and (c) of wild type CEACAM5 to immobilized recombinant CD4 peptide. (d) KD values of binding of WT CEACAM5, N ${ }^{42}$ RQII, K35A, and N70,81 A to immobilized CD8 $\alpha$ peptide. 
the affinity was equivalent to the interaction affinity between $\mathrm{CD} 8 \alpha$ and major histocompatibility complex (MHC) I (Figure 6b). ${ }^{32,33}$ The derived affinity constant was evaluated to be $2.20 \mathrm{E}-08 \mathrm{M}$ and calculated using the following on-rate and off-rate constants, $2.60 \mathrm{E}+04 \mathrm{M}-1 \mathrm{~s}-1\left(K_{\mathrm{ON}}\right)$ and 5.60E-04 s-1 $\left(K_{\mathrm{OFF}}\right)$, respectively (Figure $\left.\mathbf{6 d}\right)$. Binding of CEACAM5 to $\mathrm{CD} 8 \alpha$ was observed with as low as $50 \mathrm{~nm}$ of purified CEACAM5 protein. No binding was detected between WT CEACAM5 and recombinant CD4 protein (Figure 6c). To assess whether deletion of N42 to I46 residues in the N-terminal domain of CEACAM5 affected the binding affinity, we next studied the interaction between $\mathrm{N}^{42} \mathrm{RQII}$ and $\mathrm{CD} 8 \alpha$. Biacore analysis showed a significant and similar reduction in the $K_{\mathrm{D}}$ of $\mathrm{N}^{42} \mathrm{RQII}$ when compared with WT CEACAM5 binding to CD8 $\alpha$ $\left(K_{\mathrm{D}}=1.70 \mathrm{E}-08 \mathrm{M} ; K_{\mathrm{ON}}=9 \mathrm{E}+04 \mathrm{M}-1 \mathrm{~s}-1 ; K_{\mathrm{OFF}}=1.5 \mathrm{E}-03\right.$ s-1) (Figure 6d). Subsequently, we evaluated the interaction affinity between the different CEACAM 5 mutants to CD $8 \alpha$. Interestingly, the affinity of the mutant N70,81A CEACAM5 to $\mathrm{CD} 8 \alpha$ binding $\left(K_{\mathrm{D}}=1.60 \mathrm{E}-05 \mathrm{M} ; K_{\mathrm{ON}}=2.90 \mathrm{E}+02 \mathrm{M}-1 \mathrm{~s}-1\right)$, and $\left.K_{\mathrm{OFF}}=4.70 \mathrm{E}-03 \mathrm{~s}-1\right)$ appeared to be very low when compared with the WT CEACAM5, whereas the K35A mutant had comparable $K_{\mathrm{D}}$ value to $\mathrm{N}^{42} \mathrm{RQII}$ and WT CEACAM5 $\left(K_{\mathrm{D}}=1.50 \mathrm{E}-07 \mathrm{M} ; K_{\mathrm{ON}}=1.50 \mathrm{E}+04 \mathrm{M}-1 \mathrm{~s}-1\right.$, and $K_{\mathrm{OFF}}=$ $2.30 \mathrm{E}-03 \mathrm{~s}-1$ ) (Figure 6d). These results suggest that the loss of the initial glycosylation of CEACAM5 highly affects its conformational structure resulting in a reduction in affinity between CEACAM5 and CD $8 \alpha$.

Furthermore, we performed western blotting analysis using N70,81A CEACAM5 mutants and revealed a decrease in phosphorylation compared with WT CEACAM5 (Figure 5). To demonstrate that there is a partial overlapping binding site on CEACAM5 for both $\mathrm{B} 9 \mathrm{mAb}$ and $\mathrm{CD} 8 \alpha$, we performed a competition assay by premixing CEACAM5 peptide with B9 $\mathrm{mAb}$ and consecutively adding the mixture to $\mathrm{CD} 8 \alpha$ on the chip. As expected, no binding was observed suggesting that the B9 mAb blocks CEACAM5/CD8 $\alpha$ interactions (see Supplementary Figure S5).

\section{CEACAM5-activated $\mathrm{CD}^{+}{ }^{+} \mathrm{T}$ cells acquire suppressive functions}

IECs have been described to activate peripheral CD8 ${ }^{+} \mathrm{T}$ cells, which become potent suppressor cells. ${ }^{12}$ Moreover, lamina propria $\mathrm{CD}^{+}{ }^{-} \mathrm{T}$ cells from Crohn's disease patients have shown a reduced suppressor activity when compared with healthy controls. ${ }^{8}$ To study the function of CEACAM5activated peripheral $\mathrm{CD} 88^{+} \mathrm{T}$ cells, we first cultured freshly isolated human $\mathrm{CD}^{+} \mathrm{T}$ cells in the presence of CEACAM5 alone or in combination with IL-15 or IL-7. Previous studies using various cytokine combinations have shown that IL-7 and/ or IL-15 are critically important for the development of longterm lines in IEC:T-cell co-cultures. ${ }^{8}$ First, we assessed the expression of granzyme B in CD8 ${ }^{+} \mathrm{T}$ cells cultured for $72 \mathrm{~h}$ in the presence of CEACAM5. Granzyme B was not detectable in these conditions, suggesting that $\mathrm{CD} 8^{+} \mathrm{T}$ cells activated by CEACAM5 are not cytotoxic T cells (data not shown). Next, we performed suppression assays by assessing the ability of the stimulated $\mathrm{CD} 8{ }^{+} \mathrm{T}$ cells to suppress proliferation of $\mathrm{CD} 4^{+} \mathrm{T}$ cells. As shown in Figure 7, CD8 ${ }^{+} \mathrm{T}$ cells pre-incubated with CEACAM5 along with IL-15 strongly suppressed the proliferation of $\mathrm{CD} 4{ }^{+} \mathrm{T}$ cells to the same extent as $\mathrm{CD} 8^{+}$ $\mathrm{T}$ cells treated with anti-CD3/CD28 antibodies. Combination of CEACAM5 and IL-7 resulted in a similar but lower CD4 ${ }^{+}$ T-cell suppression when compared with CD8 ${ }^{+} \mathrm{T}$ cells preincubated with IL-15 (see Supplementary Figure S6).

\section{DISCUSSION}

Our previous studies have focused on a novel role for IECs as antigen-presenting cells. We have defined that IECs can take up soluble antigens and present them to T cells. In the normal state, such presentation results in the selective activation of $\mathrm{CD}^{+}{ }_{-}$ suppressor $\mathrm{T}$ cells. We have characterized this interaction by identifying two molecules expressed by normal IECs that bind to the T-cell receptor and to CD8 molecules on these Treg cells, CD1d and gp180, respectively. We have also generated a monoclonal antibody that specifically recognizes gp 180 . We have determined that this $\mathrm{mAb}$ was epithelial cell specific; it inhibited IEC-induced CD8 ${ }^{+}$T-cell proliferation and blocked the activation of CD8-associated Lck. This approach has led to the identification of molecules involved in IEC:T-cell interactions, specifically CD8 ${ }^{+}$T cells. Purified gp180 was shown to be important in activating Lck through binding to $\operatorname{CD} 8 \alpha$ and CD1d. ${ }^{9-20}$

CEACAM5 is an oncofetal antigen originally discovered as a cell surface molecule whose tissue and blood levels positively correlated with colorectal cancer. All members of the family have been shown to function, at least in vitro, as homotypic and heterotypic intercellular adhesion molecules. Modification in the expression of two GPI-anchored members, CEACAM5 and CEACAM6, have been shown to inhibit differentiation and anoikis, to disrupt cell polarization and tissue architecture, effects that altogether enhance tumorigenesis. Transmembrane-anchored CEACAM1, on the other hand, has none of these properties, but possesses tumor-suppressive and angiogenic effects. CEACAM1 is evolutionarily conserved, expressed in many adult tissues and mainly participates in the modulation of T-cell function to bile acid transport. GPI-anchored CEA family members evolved just before the primate radiation and the only functions ascribed to them, other than intercellular adhesion, involve the binding of their sugars to bacteria and to selectins, facilitating binding of neutrophils to vascular endothelium (a property shared by CEACAM1). ${ }^{21-31}$ More recently, CEACAM6 has been proposed as a receptor for the type 1 pili expressed by adherent-invasive Escherichia coli (AIEC), and its abnormal expression seen in Crohn's disease patients has been correlated to higher colonization and inflammation induced by AIEC. ${ }^{34}$ Previous studies from our laboratory have described a regulatory/suppressor $\mathrm{CD}^{+}{ }^{+}$T-cell population, $\mathrm{CD} 8{ }^{+} \mathrm{CD} 28^{-} \mathrm{CD} 103^{+}$population, which undergoes oligoclonal expansion in the lamina propria of the gut after interacting with an MHC class I-like complex on the basolateral surface of an epithelial cell. ${ }^{35}$ 

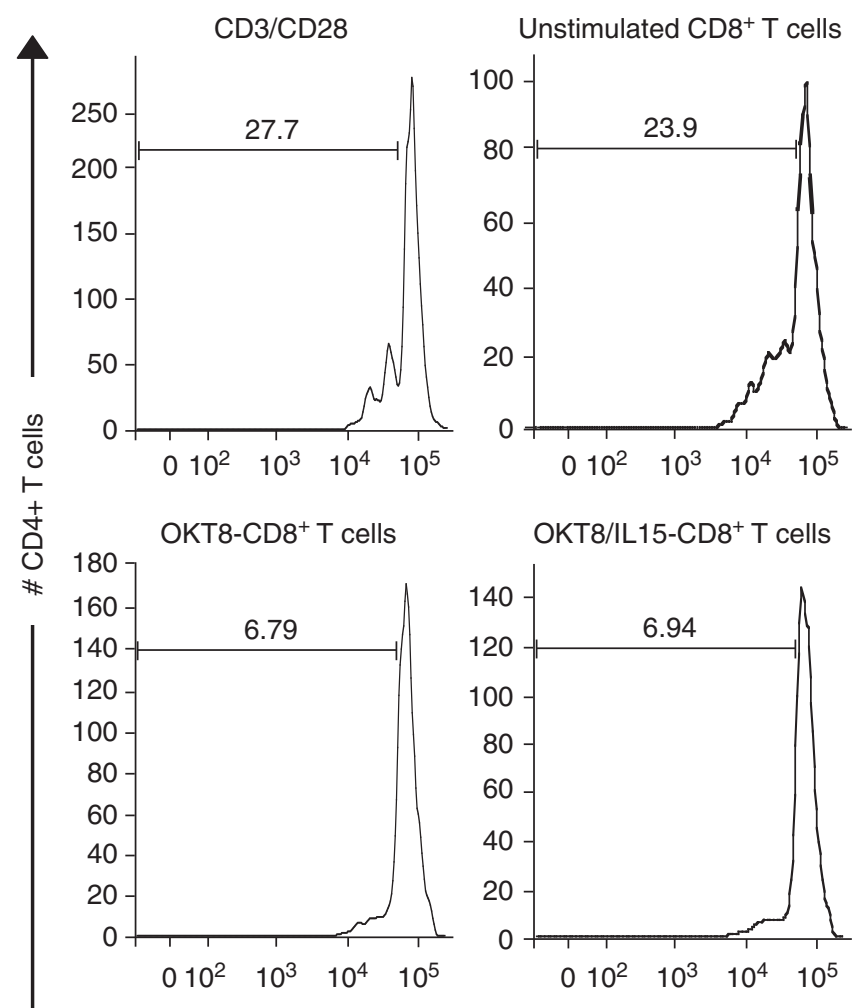
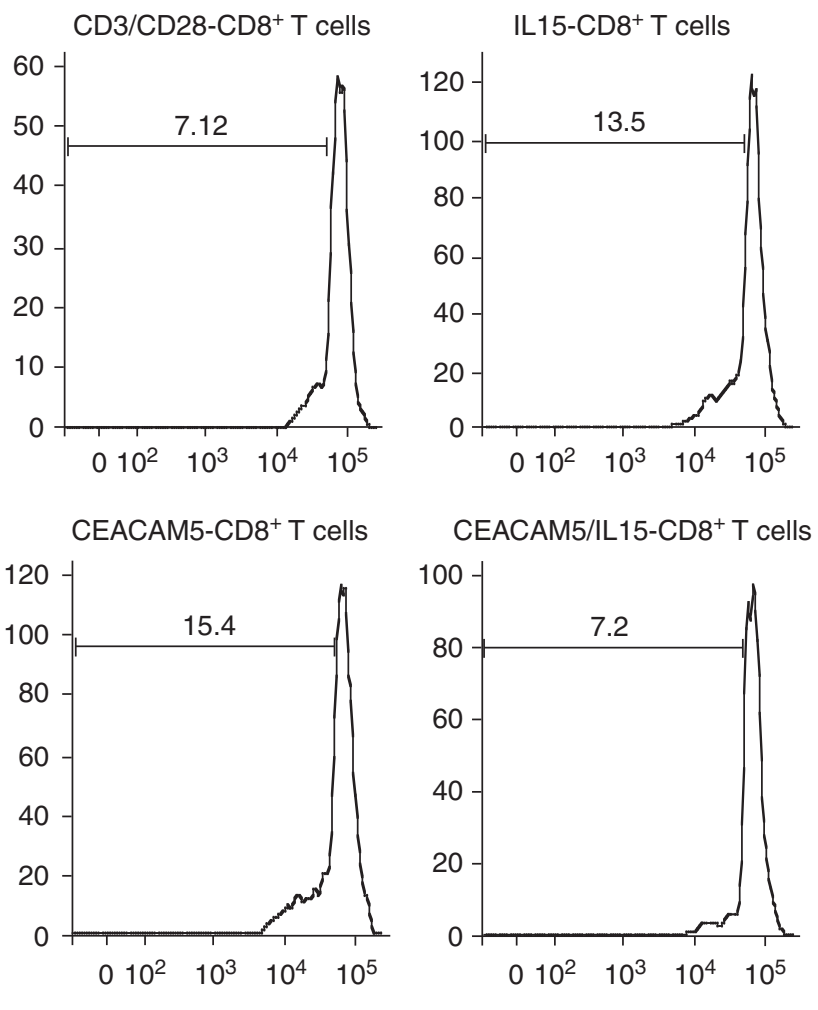

CFSE

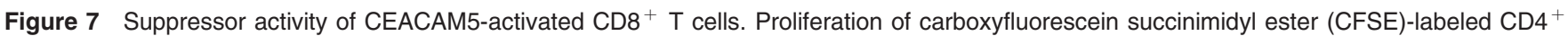

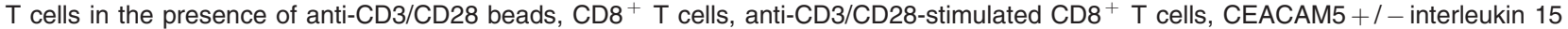
(IL15)-stimulated CD8 ${ }^{+}$T cells, and OKT8 + / - IL15-stimulated CD8 ${ }^{+}$T cells. Data are representative of four independent experiments.

In this study, we show that gp180 share homology with CEACAM5. First, we confirmed that CEACAM5 and gp180 have the same amino-acid sequence and that $\mathrm{B} 9 \mathrm{mAb}$ is capable of recognizing CEACAM5. We showed that CEACAM5 binds to $\operatorname{CD} 8 \alpha$ and induces Lck phosphorylation. Furthermore, we demonstrated that among the CEACAM family members, CEACAM5 is the only one that interacts with CD1d. We confirmed that CEACAM5 interacts with CD1d through the B3 domain and that the sugar bridge between residues 70 and 81 , which is the first highly conserved glycosylation site within the $\mathrm{N}$ domain implicated in protein-protein interactions, is crucial for CEACAM5/CD8 binding and CD8 kinase Lck activation. ${ }^{28}$ Biacore protein-protein affinity analysis validated that the N70,81A mutant strongly impacts CEACAM5/CD8 binding. Therefore glycosylation of the $\mathrm{N}$ domain of CEACAM5 is crucial for its interactions to $\mathrm{CD} 8 \alpha$. Moreover, we have proven that $\mathrm{B} 9 \mathrm{mAb}$ and $\mathrm{CD} 8 \alpha$ have affinity to a similar binding site on CEACAM5 by competition experiments. These findings corroborate with previous observations and confirmed that B9 mAb blocks the induction of CD8 ${ }^{+}$Treg cells.

Since its identification in 1965 by Gold and Freeman, ${ }^{36}$ the functional relevance of CEACAM5 and its homology to other CEA subfamily members in normal tissues has been poorly understood. It has been shown that bacterial binding to epithelial cells might be facilitated by the sugar structures present on CEACAM5 and CEACAM6. Furthermore, the abnormal expression of CEACAM6 in CD patients has been correlated with a higher bacterial colonization and increased inflammation mediated by AIEC bacteria. ${ }^{34}$ Here, we showed for the first time a novel biochemical and functional activity mediated by CEACAM5. We have proven that CEACAM5 has the ability to bind to both $\mathrm{CD} 8 \alpha$ and CD1d and hence co-activate $\mathrm{CD} 8{ }^{+} \mathrm{T}$ cells. It is possible that non-classical class-I molecules share similar features, where they complex with an additional molecule to make them more alike classical class-I or class-II molecules.

In colon cancer, CEACAM5 and CEACAM6 are dysregulated and overexpressed. ${ }^{24,25}$ It has also been described that CEACAM5 bound by liver Kupffer cells may have a role in enhancing metastasis by stimulating and producing various cytokines. ${ }^{26}$ Another CEA subfamily member, CEACAM1, is expressed on both IECs and T cells and has been shown to inhibit the cytolytic activity of intestinal intraepithelial lymphocytes, ${ }^{31}$ although activation of natural killer cells mediated by CEACAM1 has also been reported. ${ }^{30}$

For the first time, our study describes that CEACAM family members present distinct immunoregulatory functions despite their structural similarities. Only CEACAM5 interacts with CD1d. Moreover, CEACAM5 binds to CD1d and CD $8 \alpha$ through different domains. Therefore, we believe that there is constant trafficking of CEACAM5 from the membrane compartment to the intracellular compartment. Apically, 
CEACAM5 could potentially be involved in antigen uptake, while basolaterally it forms a complex with CD1d and acts as an MHC class I molecule. Epithelial antigen processing occurs in a highly polarized fashion, with apical antigens being sorted and presented exclusively basolaterally. We also believe that this unique set of interactions could facilitate antigen presentation by CD1d to $\mathrm{T}$ cells and allows the subsequent activation of $\mathrm{CD}^{+}{ }^{+}$Treg cells with potent suppressive functions (Figure 8). We previously described that IECs derived from IBD patients have a defect in the expression of CEACAM5 (gp180) due to an evident failure to activate CD8 ${ }^{+}$Treg cells. ${ }^{37}$ More recently, we generated lamina propria $\mathrm{CD} 8{ }^{+} \mathrm{T}$-suppressor lines in the presence of $\alpha \mathrm{CD} 3$ monoclonal antibody visilizumab, together with IL-15 and IL-7, and we determined that lamina propria $\mathrm{CD}^{+} \mathrm{T}$ suppressor cells from Crohn's disease patients have a reduced suppressor activity. ${ }^{8}$ Interestingly, here we extend these findings and show that CEACAM5-activated $\mathrm{CD} 8^{+}$ $\mathrm{T}$ cells acquire important suppressive functions. Hence, understanding the interactions between CEACAM5/CD1d and CD8 $\alpha / \mathrm{T}$-cell receptor in the mucosal immune system in normal individuals will allow the development of new approaches to promote induction of suppressive immune responses (in Crohn's disease) or to enhance mucosal immunity (oral vaccines).

\section{METHODS}

Purification and sequencing of gp180. gp180 purification from human IECs was performed using a mAb B9 affinity column as described previously. ${ }^{9}$ Protein sequencing was accomplished by the Protein DNA Core at the Rockefeller University.

Construction of vectors. Dual expression vector of CEACAMs and CD1d: cDNAs for CEACAM1, CEACAM5, CEACAM6, and CD1d (Genbank accession no NM_001024912, NM_004363, NM_002483, and NM_001766) were obtained by reverse transcriptase-PCR from human IEC mRNA. All of the primers are shown in Supplementary Table S1 online. An internal ribosomal entry site (IRES) was amplified from the pIRES-EGFP plasmid (Clontech, Mountain View, CA) using forward ( $5^{\prime}$-CCGAATTCATTCCGCCCCTCTCC- $\left.3^{\prime}\right)$ and reverse ( $5^{\prime}$-CCGGATCCGGGTTGTGGCAAGC) primers. Then the IRES alone (IRES), IRES-CD1d (CD1d), IRES-CEACAM5-GFP, as well as IRES-CD1d simultaneously with CEACAM1, CEACAM5, or CEAMCAM6 (CEACAM1.CD1d, CEACAM5.CD1d, and CEACAM6.CD1d) were subcloned into pcDNA3.1(-) vector (Invitrogen, Life Technology, Grand Island, NY).

Vectors expressing mutants of CEACAM5: WT CEACAM5 construct was used as a template for PCR-generated mutant constructs. For sequential C-terminal truncation, the forward primer for WT was used and the reverse primers for all the deletion mutants, including B3, A3B3, B2A3B3, B3.1, B3.2, B3.3, B3.4, and B3.5, are shown in Supplementary Table S2. Overlap extension PCR was performed to construct the expression vector for deletion of the A2 domain. The forward primer for the WT CEACAM5 and reverse primer $\left(5^{\prime}\right.$-GACGACCCCACCATTTCCCCCTCA- $\left.3^{\prime}\right)$ were used to generate fragment 1 . The forward primer $\left(5^{\prime}\right.$-GGTGGGGTCGTCG GGTGGCTCTGCATA-3') and reverse primer for WT CEACAM5 were used to generate fragment 2 . Then the cDNA with the deletion of A2 domain was generated from fragments 1 and 2 using primers for WT. The PCR fragments were subcloned into CD1d-pcDNA3.1 $(-)$. The p91023(B) vectors encoding WT and mutant CEACAM5 with deletion of $\mathrm{N} 42$ to $\mathrm{I} 46$ residues in the $\mathrm{N}$-terminal domain $\left(\mathrm{N}^{42} \mathrm{RQII}\right)$, point mutations in the $\mathrm{N}$-terminal domain $(\mathrm{K} 35 \mathrm{~A}$ and $\mathrm{N} 70,81 \mathrm{~A})$, and

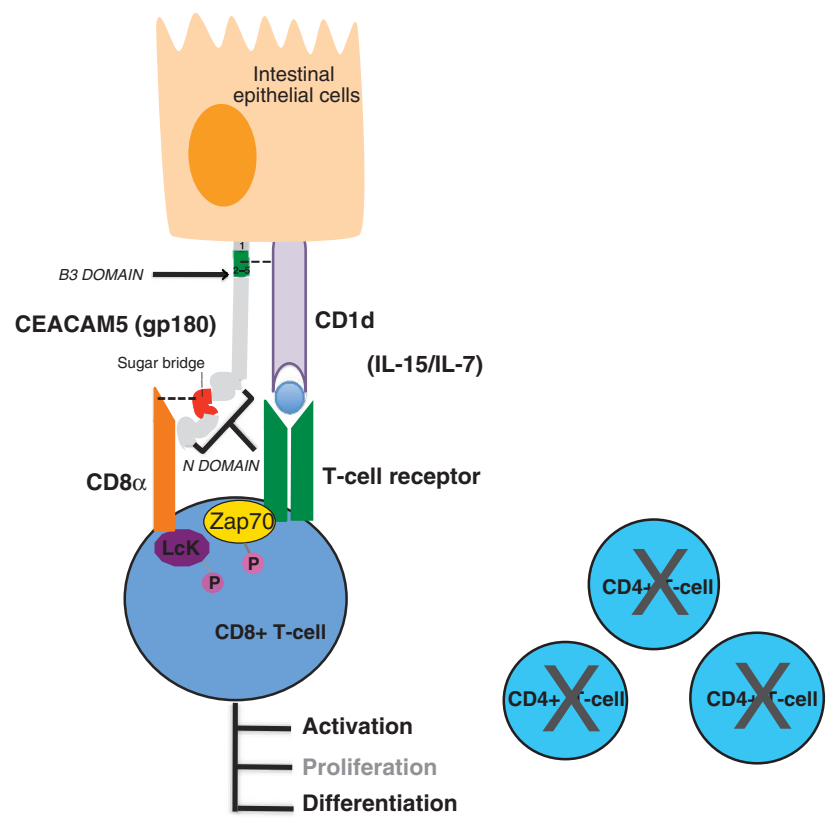

Figure 8 Interactions between CEACAM5/CD1d and CEACAM5/CD $8 \alpha$. Intestinal epithelial cells express CEACAM5 and CD1d on their surface. CEACAM5 (gp180) interacts with CD1d through the B3 domain. Fragment 1 of the $\mathrm{B} 3$ domain is not required for its interaction with CEACAM5. The sugar bridge in the $\mathrm{N}$ domain of CEACAM5 is crucial for its binding to CD8 $\alpha$ and for the activation of CD8-associated LcK. CEACAM5-activated $\mathrm{CD}^{+}{ }^{+} \mathrm{T}$ cells acquire suppressive functions and reduce the proliferation of $\mathrm{CD} 4^{+} \mathrm{T}$ cells.

CEACAM8 were generated. The sequences of all constructs were confirmed by DNA sequencing. CD $8 \alpha$ cDNA was provided by Dr P. Kavathas (Yale School of Medicine) and the extracellular domain was sub-cloned into a pcDNA 3.1/V5-His vector.

Cell culture and transfection. For transfection, a human embryonic kidney (293T), an ovarian Chinese hamster carcinoma (CHO), and a melanoma (FO-1) cell lines were used. The cells were grown at $37^{\circ} \mathrm{C}$ in Dulbecco's modified Eagle's medium (GIBCO, Carlsbad, CA) or in F-12K medium (ATCC, Manassas, VA) containing $10 \%$ fetal bovine serum (FBS) in a humidified $5 \% \mathrm{CO}_{2}$ incubator. Cells were transfected in six-well plates using Lipofectamine-2000 (Invitrogen) with $4 \mu \mathrm{g}$ of pcDNA3.1 vectors encoding CD1d alone or along with WT or truncated CEACAM5. Untransfected or cells transfected with IRES were used as controls. For the generation of stable cells expressing WT and mutant CEACAM5, cells were transfected in $100 \mathrm{~mm}$ culture plates with $12 \mu \mathrm{g}$ of $\mathrm{p} 91023$ (B) expression vectors encoding WT or mutant CEACAM5 together with $12 \mu \mathrm{g}$ of pcDNA3.1. The stable cells were established after selection with $3 \mathrm{mg} /$ ml Geneticin (G418, Sigma, St Louis, MO). Stable cells were treated with 0.1 unit $\mathrm{ml}^{-1}$ phospholipase $\mathrm{C}$, phosphatidylinositol-specific enzyme (PIPLC, Sigma) for $1 \mathrm{~h}$ at $37^{\circ} \mathrm{C}$. The supernatant was collected and subjected to western blotting using mouse Col-1 and mouse anti-gp180 (B9) monoclonal antibodies. Human IEC cell lines, HT29 and T84, were used as positive controls.

Western blots. The protein samples were subjected to 10\% SDS-PAGE (sodium dodecyl sulfate-polyacrylamide gel electrophoresis) gels, transferred to nitrocellulose membranes, and blocked with $5 \%$ milk for $1 \mathrm{~h}$ at room temperature. Membranes were incubated with primary antibodies overnight at $4{ }^{\circ} \mathrm{C}$, washed with phosphate-buffered saline (PBS) containing $0.05 \%$ Tween-20 and incubated with HRP (horseradish peroxidase)-conjugated secondary antibody (Cell Signaling, Danvers, MA) for $1 \mathrm{~h}$ at room temperature. The proteins were 
visualized using a chemiluminescent HRP substrate (Millipore, Billerica, MA).

In-cell western blot. A total of $200 \times 10^{4} \mathrm{CD} 8^{+} \mathrm{T}$ cells were seeded in a 96-well flat-bottom plate and starved in RPMI serum-free medium overnight at $37^{\circ} \mathrm{C}$. The next day and before performing the experiments, the plate was placed on ice for $15 \mathrm{~min}$. Cells were stimulated with OKT8 $\left(5 \mu \mathrm{g} \mathrm{ml}^{-1}\right)$ or purified CEACAM5 peptide $\left(10 \mu \mathrm{g} \mathrm{ml}^{-1}\right)$. Unstimulated cells were obtained for each condition. Stimulation was stopped using a $4 \%$ formaldehyde buffer for $20 \mathrm{~min}$ followed by centrifugation for $10 \mathrm{~min}$ at 1,500 r.p.m. Permeabilization was performed by washing the cells with $1 \times$ PBS containing $0.1 \%$ Triton X-100 for $5 \mathrm{~min}$ per wash. After permeabilization, cells were incubated for $1 \mathrm{~h}$ with the blocking buffer (Odyssey Blocking buffer, LICOR, Lincoln, $\mathrm{NE})$ followed by the primary antibodies goat anti-actin and rabbit anti pLcK or pZap70 overnight at $4{ }^{\circ} \mathrm{C}$. The next day, cells were washed five times with $1 \times$ PBS containing $0.1 \%$ Tween 20 , incubated for $1 \mathrm{~h}$ at room temperature with the secondary antibodies (IRDye $800 \mathrm{CW}$ donkey anti goat IgG, IRDye $680 \mathrm{CW}$ donkey anti rabbit IgG), and than washed for five times. Wells were dried, and the plate was scanned using an Odyssey LiCOR system. The software ImageStudio was used for quantification, and each well was corrected taking into consideration the actin expression and the background noise.

Flow cytometry. Trypsinized CHO cells $\left(1 \times 10^{6}\right)$ expressing CEACAM5, 1, 6, and 8 were incubated with the appropriate mAbs B9 and B18 diluted in $100 \mu \mathrm{l} \mathrm{PBS}$ containing $0.2 \% \mathrm{FBS}$ and followed by a second incubation on ice with FITC (fluorescein isothiocyanate)-labeled F(ab)' fragments of immunosorbent-purified goat anti-mouse IgG.

CEACAM5 mutants transfected CHO cells $\left(1 \times 10^{6}\right)$ were incubated with the appropriately diluted mAb T84.66 antibody in $100 \mu \mathrm{l}$ of PBS containing $0.2 \%$ FBS followed by phycoerythrin-labeled $\mathrm{F}(\mathrm{ab})_{2}{ }_{2}$ fragments of immunosorbent-purified goat anti-mouse IgG. Subsequently, cells were washed and co-stained with mAb B9 in $100 \mu \mathrm{l}$ of PBS containing $0.2 \%$ FBS followed by FITC-labeled $\mathrm{F}(\mathrm{ab})^{\prime}{ }_{2}$ fragments of immunosorbent-purified goat anti-mouse IgG. Incubations were performed on ice. The cells were then suspended in PBS plus $0.2 \%$ FBS and analyzed on a FACScan.

$\mathrm{CD} 8^{+} \mathrm{T}$ and $\mathrm{CD} 4{ }^{+} \mathrm{T}$ cells were treated for different time points $(2,8,10,15 \mathrm{~min})$ at $37^{\circ} \mathrm{C}$ with anti-CD8 $\mathrm{mAb}(\mathrm{OKT} 8)$ at $5 \mu \mathrm{gl} \mathrm{l}^{-1}$, $\mathrm{H}_{2} \mathrm{O}_{2}$ at 10 mm, CEACAM5 supernatant (Sup1) from PIPLC-293T cells expressing CECACAM5 and purified CEACAM5 peptide at $20 \mu \mathrm{g} \mathrm{ml}^{-1}$. Stimulation was stopped by fixing with $4 \%$ formaldehyde for $10 \mathrm{~min}$ at room temperature. Subsequently, cells were permeabilized with ice-cold methanol for $20 \mathrm{~min}$, washed with PBS containing $0.2 \%$ FBS, and then stained with anti-phospho-Lck Ab (BD Biosciences, San Jose, CA). The cells were then re-suspended in PBS plus $0.2 \%$ FBS, data were acquired using the FACScan system (LSRFortessa, BD Biosciences), and analyzed with FlowJo analysis software (Ashland, OR).

Co-immunoprecipitation. 293T cells were used for co-immunoprecipitation $48 \mathrm{~h}$ after transfection with the corresponding vectors as described above. Cell extracts $(150 \mu \mathrm{g}$ of protein) were incubated with $2 \mu \mathrm{g}$ of mouse IgG2b anti-CD1d (D5), mouse IgG1 anti-gp180 (B9), isotype control mouse IgG2b, or mouse IgG1 for $4 \mathrm{~h}$ at $4{ }^{\circ} \mathrm{C}$, followed by the addition of $10 \mu \mathrm{l}$ protein $\mathrm{G}$ Sepharose (Amersham Biosciences, Piscataway, NJ) for $12 \mathrm{~h}$. Pellets were washed three times with RIPA buffer (10 mm Tris, pH 8.0, $1.0 \mathrm{~mm}$ EDTA, 0.5\% Nonidet P-40, $0.1 \mathrm{M}$ $\mathrm{NaCl}$ ), boiled in SDS sample buffer, and resolved on SDS-PAGE gels. After transferring to nitrocellulose, an anti-CEA mAb (Col-1) (Dako, Produktionsvej, Glostrup, Denmark) followed by a CD1d mAb D5 western blot was performed.

Absorption assay. In all, $10 \mu \mathrm{l}$ of PIPLC-treated supernatants from 293T/CEACAM5 cells or from confluent T84 cells were incubated on ice with $14 \times 10^{6} 3 \mathrm{G} 4$ (mouse T-cell hybridoma transfected with human $\mathrm{CD} 4 \mathrm{cDNA}$ ) or $3 \mathrm{G} 8$ (mouse T-cell hybridoma transfected with human CD8 cDNA) cells for $1 \mathrm{~h}$. After incubation, $20 \mu \mathrm{l}$ of RPMI were added to each tube to facilitate collection of the absorbed supernatants. Supernatants (Sup2) were collected following centrifugation at 13,000 r.p.m. for $2 \mathrm{~min}$. The entire $30 \mu \mathrm{l}$ was resolved in $8 \%$ SDS-PAGE and subjected to western blotting analysis.

Protein purification. The supernatant obtained from treated PIPLCtransfected $\mathrm{CHO}$ cell lines was collected and subjected to mouse antiCEA (Col-1) mAb Western blotting. Supernatants expressing CEA were subjected to a Col-1 Ab (A/B domain specific) purification column, to dialysis using dialysis membrane tubing with molecular weight cutoff of 12,000-14,000, and to concentration using Vivaspin 6 columns. Supernatant obtained from CD8 $\alpha$-transfected 293T cells containing the extracellular domain of $\mathrm{CD} 8 \alpha$ was collected and subjected to a mouse monoclonal anti-CD $8 \alpha$ antibody western blotting. Supernatant expressing CD8 $\alpha$ was purified using the Probond purification System-Invitrogen specific for polyhistidine-containing recombinant proteins. Eluted protein was then subjected to dialysis and concentration. Eluted proteins were finally subjected to $\mathrm{mAb}$ Col-1 (Zymed, Life Technology) and $\mathrm{mAb} C D 8 \alpha$ western blotting (Santa Cruz, Dallas, TX) to confirm the presence of full-length and mutants CEACAM5s and CD $8 \alpha$.

Biacore kinetic analyses. As assay buffer, we used $10 \mathrm{mM}$ HEPES buffer ( $\mathrm{pH} 7.4$ ), $150 \mathrm{~mm} \mathrm{NaCl}, 3 \mathrm{~mm}$ EDTA, and $0.005 \%$ P20 (polyoxyethylenesorbitan); as regeneration buffer we used $50 \mathrm{~mm}$ Tris, $2 \mathrm{M} \mathrm{NaCl}$, and $\mathrm{pH}$ 7.3; and as conjugation buffer we used $10 \mathrm{~mm}$ sodium acetate buffer ( $\mathrm{pH}$ 5.0). Purified $\mathrm{CD} 8 \alpha$ protein was directly immobilized to the high-capacity carboxymethylated dextran and covalently attached to a gold surface (CM5 chip) by amine coupling chemistry. The amount $\left(R_{\mathrm{L}}\right)$ of protein to be captured on the chip was determined by the following formula: $R_{\mathrm{Max}}=\mathrm{MW}_{\mathrm{A}} / \mathrm{MW}_{\mathrm{L}} \bullet R_{\mathrm{L}}$ where $\mathrm{MW}_{\mathrm{A}}$ is the molecular weight of the analyte (CEACAM5) $(180 \mathrm{KDa})$ and $\mathrm{MW}_{\mathrm{L}}$ is the molecular weight of the ligand $(\mathrm{CD} 8 \alpha)(19 \mathrm{KDa}) . R_{\mathrm{Max}}$ corresponds to the maximum resonance unit that we obtained during analyses. We set $R_{\text {Max }}<50$ for antibody/antigen interactions. $R_{\mathrm{L}}$ corresponds to the refractory index of the ligand and is expressed in resonance units (RU). $R_{\mathrm{MAX}}$ of 50 was $R_{\mathrm{L}}=50 \times 19 / 180=5.3$. We captured the ligand onto the chip until it reached 5.3 RU. RU is a Resonance Unit generated by the shift of refractory index due to ligand-analyte interactions on a sensor chip. $K_{\mathrm{D}}$ is defined as $K_{\mathrm{D}}=K \mathrm{~d} / K \mathrm{Ka}$.

Biacore measures real-time $K \mathrm{Ka}$ (on rate) and $K \mathrm{~d}$ (off rate) based on its curve-fitting program. The flow rate used for capturing ligand is $5 \mathrm{ml} \mathrm{min}^{-1}$. For kinetic analysis, the flow rate of $30 \mathrm{ml} \mathrm{min}^{-1}$ is used for the analyte. The first run is the scouting analysis using high concentrations of analyte. For the assays, we used $200 \mathrm{~nm}$. At this concentration, binding should be observed even if the ligand-binding affinity is weak. The scouting analysis provides a rough $K_{\mathrm{D}}$. Based on the rough $K_{\mathrm{D}}$ value, full kinetics analyses are performed using five analyte concentrations slightly above the $K_{\mathrm{D}}$ to zero. Chi square $\left(\chi^{2}\right)$ analysis on the $K_{\mathrm{D}}$ values obtained from each analyte concentration was performed to determine the statistical accuracy of the measured $K_{\mathrm{D}} \cdot \chi^{2}$ value of $\sim 2$ is considered significant (accurate) and $<1$ is highly significant (highly accurate). After each assay, the chip is treated with $50 \mathrm{~mm}$ Tris, $2 \mathrm{M} \mathrm{NaCl}$, and $\mathrm{pH} 7.3$ to remove the ligand and the analyte for regeneration.

In vitro suppression assay. To evaluate the effect of CEACAM5activated $\mathrm{CD}^{+} \mathrm{T}$ cells on anti-CD3/CD28 antibody-stimulated peripheral $\mathrm{CD}^{+}{ }^{+} \mathrm{T}$ cells. $\mathrm{CD} 8{ }^{+} \mathrm{T}$ cells and $\mathrm{CD} 4{ }^{+} \mathrm{T}$ cells were positively selected using, respectively, a CD8 ${ }^{+}$and $\mathrm{CD}^{+}{ }^{+} \mathrm{T}$-cell selection kits (Stemcell Technologies, Vancouver, BC, Canada). CD8 ${ }^{+}$ $\mathrm{T}$ cells were incubated for 3 days in the presence or absence of purified CEACAM5 or OKT8 in combination with IL-15 or IL-7. Anti-CD3/ CD28 beads were used as positive controls. Purified CEACAM5 and OKT8 were added every day for 3 days. Then cells were washed, counted, and added at a ratio of 1:1 to peripheral CD4 ${ }^{+} \mathrm{T}$ cells labeled with carboxyfluorescein succinimidyl ester (CFSE) (Invitrogen) and either unstimulated or stimulated with anti-CD3/CD28 beads. 
Proliferation of CD4 ${ }^{+}$T cells measured by CFSE dilution was analyzed by flow cytometry.

SUPPLEMENTARY MATERIAL is linked to the online version of the paper at http://www.nature.com/mi

\section{ACKNOWLEDGMENTS}

This work was supported by NIH grants AI044236, AI084952, DK072201, and DK086605 and a grant from the CCFA. GY has been supported by a grant of Hemsley Trust.

\section{DISCLOSURE}

The authors declared no conflict of interest.

(c) 2014 Society for Mucosal Immunology

\section{REFERENCES}

1. Bland, P.W. MHC class II expression by the gut epithelium. Immunol. Today 9, 174-178 (1988).

2. Bland, P.W. \& Warren, L.G. Antigen presentation by epithelial cells of the rat small intestine. II. Selective induction of suppressor Tcells. Immunology $\mathbf{5 8}$ 9-14 (1986).

3. Bland, P.W. \& Whiting, C.V. Antigen processing by isolated rat intestinal villus enterocytes. Immunology 68, 497-502 (1989).

4. Hershberg, R. et al. Expression of the thymus leukemia antigen in mouse intestinal epithelium. Proc. Natl. Acad. Sci. 87, 9727-9731 (1990).

5. Hershberg, R.M. et al. Intestinal epithelial cells use two distinct pathways for HLA class II antigen processing. J. Clin. Invest. 100, 204-215 (1997).

6. Kaiserlian, D, Vidal, K \& Revillard, J.P. Murine enterocytes can present soluble antigen to specific class II restricted CD4 + Tcells. Eur. J. Immunol. 19, 1513-1516 (1989).

7. Mayer, L, So, L.P., Yio, X.Y. \& Small, G. Antigen trafficking in the intestine. Ann. NY Acad. Sci. 778, 28-35 (1996).

8. Rabinowitz, K.M. et al. Transforming growth factor $\beta$ signaling controls activities of human intestinal CD8(+)T suppressor cells. Gastroenterology 144, 601-612 (2013).

9. Yio, X.Y. \& Mayer, L. Characterization of a 180-kDa intestinal epithelial cell membrane glycoprotein, gp180 A candidate molecule mediating t cellepithelial cell interactions. J. Biol. Chem. 272, 12786-12792 (1997).

10. Campbell, N.A. et al. A non-class I MHC intestinal epithelial surface glycoprotein, gp180, binds to CD8. Clin. Immunol. 102, 267-274 (2002).

11. Campbell, N.A., Kim, H.S., Blumberg, R.S. \& Mayer, L. The nonclassical class I molecule CD1d associates with the novel CD8 ligand gp180 on intestinal epithelial cells. Biol. Chem. 274, 26259-26265 (1999).

12. Allez, M, Brimnes, J, Dotan, I \& Mayer, L. Expansion of CD8 + T cells with regulatory function after interaction with intestinal epithelial cells. Gastroenterology 123, 1516-1526 (2002).

13. Allez, M, Brimnes, J, Shao, L, Dotan, I, Nakasawa, A \& Mayer, L. Activation of a unique population of $\mathrm{CD} 8(+) \mathrm{T}$ cells by intestinal epithelial cells. Ann. NY Acad. Sci. 1029, 22-35 (2004).

14. Allez, M \& Mayer, L. Regulatory T cells: peace keepers in the gut. Inflamm. Bowel Dis. 10, 666-676 (2004).

15. Arosa, F.A., Irwin, C, Mayer, L, de Sousa, M \& Posnett, D.N. Interactions between peripheral blood CD8 T lymphocytes and intestinal epithelial cells (IEC). Clin. Exp. Immunol. 112, 226-236 (1998).

16. Li, Y, Yio, X.Y. \& Mayer, L. Human intestinal epithelial cell-induced CD8 + $\mathrm{T}$ cell activation is mediated through CD8 and the activation of CD8associated p56Lck. J. Exp. Med. 182, 1079-1088 (1995).
17. Mayer, L. IBD: immunologic research at The Mount Sinai Hospital. Mt Sinai J. Med. 67, 208-213 (2000)

18. Somnay-Wadgaonkar, K. et al. Immunolocalization of CD1d in human intestinal epithelial cells and identification of a beta2-microglobulinassociated form. Int. Immunol. 11, 383-392 (1999).

19. Van de Wal, Y. et al. Delineation of a CD1d-restricted antigen presentation pathway associated with human and mouse intestinal epithelial cells. Gastroenterology 124, 1420-1431 (2003).

20. Toy, L.S., Yio, X.Y., Lin, A, Honing, S \& Mayer, L. Defective expression of gp180, a novel. CD8 ligand on intestinal epithelial cells, in inflammatory bowel disease. J. Clin. Invest. 100, 2062-2071 (1997).

21. Hammarström, S. The carcinoembryonic antigen (CEA) family: structures, suggested functions and expression in normal and malignant tissues. Semin. Cancer Biol. 9, 67-81 (1999).

22. Kinugasa, T. et al. Expression of four CEA family antigens (CEA, NCA, BGP and CGM2) in normal and cancerous gastric epithelial cells: up-regulation of BGP and CGM2 in carcinomas. Int. J. Cancer 76, 148-153 (1998).

23. Frangsmyr, L, Baranov, V \& Hammarstrom, S. Four carcinoembryonic antigen subfamily members, CEA, NCA, BGP and CGM2, selectively expressed in the normal human colonic epithelium, are integral components of the fuzzy coat. Tumour Biol. 20, 277-292 (1999).

24. Kuespert, K, Pils, S \& Hauck, C.R. CEACAMs: their role in physiology and pathophysiology. Curr. Opin. Cell Biol. 18, 565-571 (2006).

25. Yan, Z. et al. Oncogenic c-Ki-ras but not oncogenic c-Ha-ras up-regulates CEA expression and disrupts basolateral polarity in colon epithelial cells. J. Biol. Chem. 272, 27902-27907 (1997).

26. Ordonez, C, Screaton, R.A., Ilantzis, C \& Stanners, C.P. Human carcinoembryonic antigen functions as a general inhibitor of anoikis. Cancer Res. 60, 3419-3424 (2000).

27. Wirth, T, Soeth, E, Czubayko, F \& Juhl, H. Inhibition of endogenous carcinoembryonic in Crohn disease antigen (CEA) increases the apoptotic rate of colon cancer cells and inhibits metastatic tumor growth. Clin. Exp. Metastasis 19, 155-160 (2002).

28. Bates, P.A., Luo, J \& Sternberg, M.J. A predicted three-dimensional structure for the carcinoembryonic antigen (CEA). FEBS Lett. 301, 207-214 (1992).

29. Gangopadhyay, A, Lazure, D.A. \& Thomas, P. Adhesion of colorectal carcinoma cells to the endothelium is mediated by cytokines from CEA stimulated Kupffer cells. Clin. Exp. Metastasis 8, 703-712 (1998).

30. Morales, V.M. et al. Regulation of human intestinal intraepithelia lymphocyte cytolytic function by biliary glycoprotein (CD66a). J. Immunol. 163, 1363-1370 (1999).

31. Kammerer, R, Stober, D, Singer, B.B., Obrink, B \& Reimann, J. Carcinoembryonic antigen-related cell adhesion molecule 1 on murine dendritic cells is a potent regulator of T cell stimulation. J. Immunol. 166, 6537-6544 (2001).

32. Huang, J, Lindsay, J, Evavold, B.D. \& Cheng, Z. Kinetic of the MHC-CD8 interaction at the T cell membrane. J. Immunol. 179, 7653-7662 (2007).

33. Jelonek, M.T., Classon, B.J., Hudson, P.J. \& Margulies, D.H. Direct binding of the $\mathrm{MHC}$ class I molecule H-2Ld to CD8: interaction with the amino terminus of a mature cell surface protein. J. Immunol. 160, 2809-2814 (1998).

34. Barnich, N \& Darfeuille-Michaud, A. Abnormal CEACAM6 expression patients favors gut colonization and inflammation by adherent-invasive $\mathrm{E}$. coli. Virulence 1, 281-282 (2010).

35. Dahan, S, Roth-Walter, F, Arnaboldi, P, Argawal, S \& Mayer, L. Epithelia: lymphocyte interactions in the gut. Immunol. Rev. 215, 243-253 (2007).

36. Gold, P \& Freedman, SO. Demonstration of tumor-specific antigens in human colonic carcinomata by immunological tolerance and absorption techniques. J. Exp. Med. 121, 439-462 (1965).

37. Roda, G. et al. Defect in CEACAM family member expression in Crohn's disease IECs is regulated by the transcription factor SOX9. Inflamm. Bowel Dis. 15, 1775-1783 (2009). 